\title{
Polymorphisms of toll-like receptor 2 and 4 genes in Chagas disease
}

\author{
German Zafra, Oscar Flórez, Carlos A. Morillo', Luis Eduardo Echeverría², Javier Martín³, \\ Clara Isabel González/+
}

\begin{abstract}
Grupo de Inmunología y Epidemiología Molecular, Escuela de Bacteriología, Facultad de Salud, Universidad Industrial de Santander, Carrera 32 \#29-31, Bucaramanga, Colombia ${ }^{1}$ Grupo de Investigación en Sistema Nervioso Autónomo, Fundación Cardiovascular de Colombia, Floridablanca, Colombia, Department of Medicine, McMaster University, Canada ${ }^{2}$ Grupo de Investigación en Ciencias Cardiovasculares, Fundación Cardiovascular de Colombia, Floridablanca, Colombia ${ }^{3}$ Instituto de Parasitología y Biomedicina López-Neyra, CSIC Granada, Spain
\end{abstract}

The aim of this study was to test the possible implication of toll-like receptor 2 (TLR2) and TLR4 gene polymorphisms in determining the susceptibility to Chagas' disease. Genotypes were determined by polymerase chain reaction-restriction fragment length polymorphism in 475 individuals from Colombia, 143 seropositive with chagasic cardiomyopathy, 132 seropositive asymptomatic and 200 seronegative. The TLR2 arginine to glutamine substitution at residue 753 (Arg753Gln) polymorphism was absent in the groups analyzed. The TLR4 Asp299Gly and Thr399Ile polymorphisms are in linkage disequilibrium and we observed a very low frequency of these polymorphisms in our study population (2.6\% and $1.8 \%$ respectively). The overall TLR2 and TLR4 alleles and genotype distribution in seronegative and seropositive were not significantly different. We compared the frequencies between asymptomatic patients and those with chagasic cardiomyopathy and we did not observe any significant differences in the distribution of alleles or genotypes. In summary, this study corroborates the low frequency of TLR2 and TLR4 polymorphisms observed in other populations and suggest that these do not play an important role in Chagas'disease. The validation of these findings in independent cohorts is needed to firmly establish a role for TLR2 and TLR4 variants in Chagas'disease.

Key words: Chagas' disease - polymorphism - toll-like receptor 2 gene - toll-like receptor 4 gene

Chagas' disease (CD) is caused by infection with the intracellular protozoan parasite, Trypanosoma cruzi, and is the major cause of cardiomyopathy and heart failure in endemic regions of Colombia and South America (Guhl 1999, WHO 2002). A wide clinical spectrum is observed in the chronic phase of $\mathrm{CD}$, varying from a relatively benign indeterminate form to gastrointestinal compromise or chronic cardiomyopathy that is usually fatal. The fact that only $20-30 \%$ of the infected individuals develop cardiomyopathy suggests a differential set of physiopathologic events between infected individuals. Differences in the expression of genes related to the immune response may be involved. In humans there are studies addressing the relation between the major histocompatibility complex genes and CD (Nieto et al. 2000). In addition, the $\mathrm{C} 3 \mathrm{~F}$ allele has been proposed as a marker for the progression of cardiomyopathy (Messias-Reason et al. 2003). Cytokine and chemokine genes have been implicated in determining increased susceptibility and further development of chagasic heart disease (Calzada et al. 2001, Flórez et al. 2006, Zafra et al. 2007). Genetic susceptibility to T. cruzi infection and the development of cardiomyopathy is complex and heterogeneous and likely involves several genes.

Finnancial support: Grant 1102-04-12901 from Colciencias, and Universidad Industrial de Santander, Bucaramanga, Colombia.

+ Corresponding author: cig@uis.edu.co

Received 4 June 2007

Accepted 11 February 2008
The toll-like receptor family (TLRs) is a major class of eukaryotic receptors for microbial pathogens associated molecular patterns (PAMPs) and endogenous ligands. When TLRs recognize PAMPs induce signals responsible for the activation of genes relevant to the host defence including inflammatory and adaptative immunerelated cytokines (Takeda et al. 2003). Some of the microbial components recognized by these receptors have been identified. TLR2 recognizes a variety of microbial components such as lipoproteins from various pathogens, and lipoarabinomannan from mycobacteria and zymosan from fungi, among others. TLR4 recognizes principally lipopolysaccharide from Gram-negative bacteria (Takeda \& Akira 2005). In protozoa, Plasmodium falciparum glycosylphosphatidylinositol (GPI) was reported to induce signaling via both TLR-2 and TLR-4 (Krishnegowda et al. 2005). GPI anchors of T. cruzi are recognized by TLR2 (Campos et al. 2004). In addition T. cruzi Tc52 released protein and glycoinositolphospholipid, stimulating murine macrophages via TLR2 and TLR4 (Ouassi et al. 2002, Oliveira et al. 2004). Unmethylated CpG motifs of T. cruzi DNA also stimulate macrophages, dendritic cells and B lymphocytes probably via TLR-9 (Shoda et al. 2001). Some reports have shown that TLR-2, TLR-4 and the related signalling pathway play an important role in the initial recognition of $T$. cruzi and may regulate the initial pro-inflammatory response during infection with the parasite but may also contribute to the severity of the disease (Almeida \& Gazzinelli 2001, Gazzinelli et al. 2004).

Genetic variations in TLR genes correlate with several infectious diseases (Schroder et al. 2005). Several single-nucleotide polymorphism (SNPs) have been described for the TLR2 and TLR4 genes. The TLR2 argin- 
ine to glutamine substitution at residue 753 (Arg753Gln) have been described to increase the risk of tuberculosis (Ogus et al. 2004, Ben-Ali et al. 2004). For TLR4, two frequently co-segregating polymorphisms (Asp299GlyThr399Ile) are at increased risk of septic shock (Lorenz et al. 2002), Gram-negative infection (Genc et al. 2004) and, severe malaria (Mockenhaupt et al 2006).

The aim of this study was to investigate the possible association of these TLR2 and TLR4 gene polymorphisms with the susceptibility to T. cruzi infection and the development of chagasic cardiomyopathy (CC).

\section{SUBJECTS, MATERIALS AND METHODS}

Study subjects - The study included 275 chagasic patients from the Department of Santander, Colombia, who were serologically positive for $T$. cruzi antigens and 200 serologically negative individuals. Both seropositive and seronegative patients are from an endemic area in Northeastern Colombia, where aproximately $50 \%$ of individuals are seropositive for T. cruzi infection (Gutiérrez et al. 2004). All participants were older than 28 years, the mean age of the seronegative group was 41 years, the mean age of the asymptomatic group was 48.7 years and the mean age of the cardiomyopathic group was 55.2 years; $61 \%$ of seronegative, $68.9 \%$ of asymptomatic and $61.5 \%$ of cardiomyopathic were female. The serological diagnosis was based on enzyme-linked immunosorbent assay and indirect hemagglutination test. Patients were classified according to clinical and electrocardiographic characteristics. Those without cardiac symptoms and with normal electrocardiogram (ECG) were classified as asymptomatic while patients that by clinical evaluation, electrocardiogram, Holter $(24 \mathrm{~h})$ and echocardiogram showed conduction alterations and/or structural cardiomyopathy were included in the cardiomyopathic or symptomatic group as follows: CC II ( $\mathrm{n}=30$, normal or with radiology indicative of light heart hypertrophy or minor ECG alterations), CC III $(\mathrm{n}=83$, moderate heart hypertrophy and considerable ECG alterations, mainly advanced conduction abnormalities) and CC IV $(n=30$, severe cardiomegaly and marked ECG alterations, predominantly frequent and/or complex forms of ventricular arrhythmia) (Rocha et al. 2003). All the individuals are from the same geographic region and have been living there for more than ten years. The population from the region is a homogeneous mixture and there is no specific concentration of any ethnicity. The Ethics Committee of each institution approved this study and written informed consent was obtained from all the subjects.

Genotyping - Genomic DNA was isolated from $7 \mathrm{ml}$ of EDTA-anticoagulated blood sample using the standard salting-out technique (Miller et al. 1988). Genotyping was performed by the polymerase chain reaction - restriction fragment length polymorphisms method for Arg753Gln TLR2 polymorphism and, Asp299Gly and Thr399Ile TLR4 polymorphisms (Lorenz et al. 2001).

Sample size calculations - The power of the sample size was calculated using the Quanto software, version 1.1. (Gauderman \& Morrison 2006) using an unmatched (1:0.72) case-control design, and a gene only hypothesis.
We calculated power for analyzed SNPs to confirm the effect. In our case-control study, we had a power of 0.8767 for TLR2 Arg753Gln, 0.8982 for TLR4 Asp299Gly and 0.8982 for TLR4 Thr399Ile, assuming a two-sided $\alpha$-level of 0.05 and a dominant heredity pattern.

Statistical analysis - Allele and genotype frequencies were obtained by direct counting. Differences between allele and genotype frequencies were determined using $\chi^{2}$ test. Odds ratios and $95 \%$ confidence intervals were calculated according to Woolf's method. The software used was Statcalc EpiInfo 2002 (Centers for Disease Control and Prevention, Atlanta, GA). A p $<0.05$ was considered as statistically significant.

\section{RESULTS}

The TLR4 genotypic and allelic frequencies analyzed in cardiomyopathic, asymptomatic patients and seronegative individuals are listed in Table.

In TLR2 gene the Arg753Gln polymorphism was completely absent in all cases and controls with $100 \%$ of homozygotes for the AA genotype (Gln/Gln). Regarding TLR 4 polymorphisms, the $4.2 \%$ of symptomatic subjects, $3 \%$ asymptomatic and $4.5 \%$ of the seronegative were heterozygous for the Asp299Gly variant, while 0.7\%, $1.5 \%$ and $0 \%$ respectively were homozygous for polymorphism. No homozygous TT genotype for the TLR4 Thr399Ile was observed, and the heterozygous frequency in symptomatic subjects was $2.8 \%, 3 \%$ in asymptomatic individuals and $4.5 \%$ in the seronegative group (Table). No statistically significant differences were observed in the TLR4 299 or TLR4 399 allele frequencies when the seropositive and seronegative groups were compared $(\mathrm{p}=0.53 ; \mathrm{OR}=1.3 ; 95 \% \mathrm{CI} 0.54-3.22 ; \mathrm{p}=0.36$; $\mathrm{OR}=0.64 ; 95 \%$ CI $0.22-1.83$, respectively).

In order to investigate the possible influence of TLR2 and TLR4 variants in the development of CC, TLR2 and TLR4 genotype frequencies between asymptomatic patients and those with $\mathrm{CC}$ were compared. We failed to detect significant differences in the distribution of TLR2 and TLR4 allele and genotypes between asymptomatic and $\mathrm{CC}$ individuals probably due to the low frequency of the polymorphisms in the studied population (Table).

\section{DISCUSSION}

The heterogeneity in the clinical expression of CD strongly suggests the involvement of genetic factors on its pathogenesis. A number of studies suggest that variation in genes encoding proteins involved in mediating the immune response to the parasite, could contribute to the individual susceptibility to develop the CC (Calzada et al. 2001, Flórez et al. 2006, Drigo et al. 2006, Ramasawmy et al. 2006). This is the first report to analyze multiple polymorphic markers in the TLR2 and TLR4 genes seeking an association between T. cruzi infection and susceptibility to develop cardiomyopathy in CD. In this study, we investigated TLR2 and TLR4 genetic polymorphisms in CD in a case-control study in an endemic region in Colombia. We were unable to provided any evidence for an association of the SNPs investigated and their role with susceptibility developing cardiomyopathy 
TABLE

Toll-like receptor 4 (TLR4) allele and genotype frequencies in patients with chagasic cardiomyopathy (CC), asymptomatic and seronegative individuals in a Colombian population

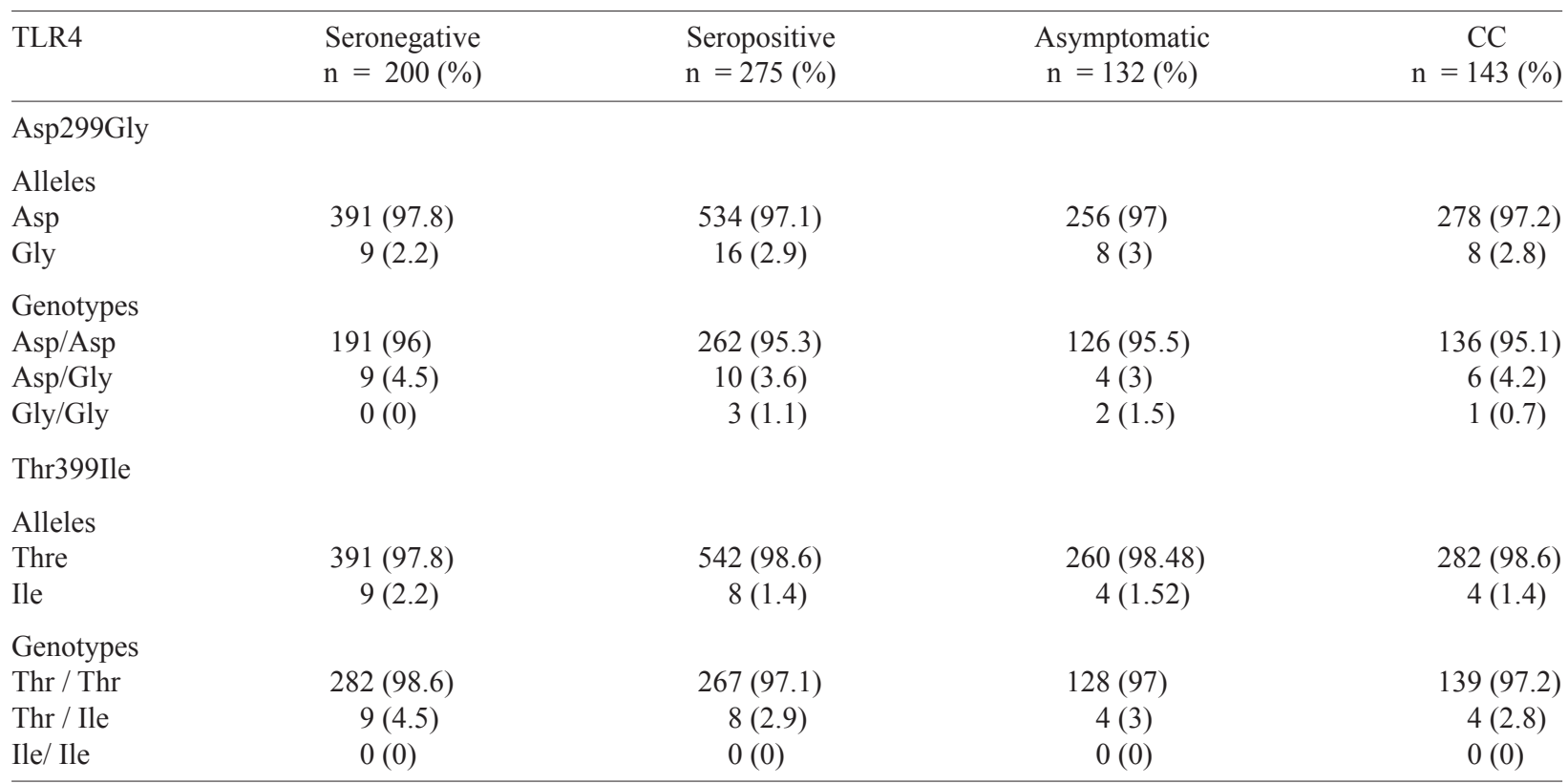

in T. cruzi infected subjects. These results may be related to the very low allele frequency of these polymorphisms in the studied population. Significant differences in allele frequencies have been reported between ethnically diverse populations. The TLR2 Arg753Gln polymorphism which is absent in our population, is similar to that observed in a case-control study among Ghanaian children (Mockenhaupt et al. 2006). In European populations the frequency varies between 6-14\% (Folwaczny et al. 2004, Lorenz et al. 2001). Frequent SNPs for TLR2 have been described associated with susceptibility to infectious diseases such as lepromatous leprosy (Kang \& Chae 2001) and tuberculosis (Ben-Ali et al. 2004).

In the TLR4 gene we observed that the Asp299Gly and the Thr399Ile polymorphisms are in linkage disequilibrium, although this disequilibrium did not seem to be complete. A very low frequency of these polymorphisms was observed in our study population, 2.6\% for Asp299Gly and 1.8\% for Thr399Ile compared with similar studies in Spanish and German populations (Schroder et al. 2003, Sánchez et al. 2004). These polymorphisms have been observed associated with severe malaria (Mockenhaupt et al. 2006) and Gram-negative infection (Genc et al. 2004). In T. cruzi infection, both in vitro and knockout mice studies, have shown that innate immunity plays a crucial role in resistance to infection, as well as in parasite-induced cytokine response, TLR4-mutant mice were susceptible to T. cruzi infection with higher parasitemia showing earlier mortality (Campos et al. 2004, Oliveira et al. 2004). Although we did not observe any statistically significant differences in the genotype or allele distribution between case and control groups, these results do not exclude the role that these polymorphisms may have in determining susceptibility to developing CC possibly due to the low frequency observed. A larger sample size may be required in order to establish whether a cause-effect association exists between these polymorphisms and susceptibility to infection and/or to development of cardiomyopathy.

In conclusion, this study corroborates the low frequency of the TLR2 Arg753Gln, TLR4 Asp299Gly and the Thr399Ile polymorphisms observed in other populations. Our data suggest that TLR2 and TLR4 genes polymorphism do not play a significant role in patients with $\mathrm{CD}$. The validation of these findings in independent cohorts is needed to firmly establish the role of TLR2 and TLR4 variants in subjects with CD.

\section{ACKNOWLEDGMENTS}

To our patients from an endemic region in Santander. To Jose Herman Arteaga for critically reading this manuscript, and Franklin Quiros and Wilfredo Valdivieso for technical assistance.

\section{REFERENCES}

Almeida IC, Gazzinelli RT 2001. Proinflammatory activity of glycosylphosphatidylinositol anchors derived from Trypanosoma cru$z i$ : structural and functional analyses. J Leukoc Biol 70: 467-477.

Ben-Ali M, Barbouche MR, Bousnina S, Chabbou A, Dellagi K 2004. Toll-like receptor 2 Arg677Trp polymorphism is associated with susceptibility to tuberculosis in Tunisian patients. Clin Diagn Lab Immunol 11: 625-626.

Berdeli A, Celik HA, Özyürek R, Dogrusoz B, Aydin HH 2005. TLR-2 gene Arg753Gln polymorphism is strongly associated with acute rheumatic fever in children. J Mol Med 83: 535-541.

Calzada JE, Nieto A, Beraun Y, Martin J 2001. Chemokine receptor 
CCR5 polymorphisms and Chagas' disease cardiomyopathy. Tissue Antigens 58: 154-158.

Campos MA, Closel M, Valente EP, Cardoso JE, Akira S, AlvarezLeite JI, Ropert C, Gazzinelli RT 2004. Impaired production of proinflammatory cytokines and host resistance to acute infection with Trypanosoma cruzi in mice lacking functional myeloid differentiation factor 88. J Immunol 172: 1711-1718.

Drigo SA, Cunha-Neto E, Ianni B, Cardoso MR, Braga PE, Fae KC, Nunes VL, Buck P, Mady C, Kalil J, Goldberg AC 2006. TNF gene polymorphisms are associated with reduced survival in severe Chagas' disease cardiomyopathy patients. Microbes Infect 8: 598-603.

Flórez O, Zafra G, Morillo C, Martín J, González CI 2006. Interleukin-1 gene cluster polymorphism in Chagas Disease in a Colombian case-control study. Hum Immunol 67: 741-748.

Folwaczny M, Glas J, Torok HP, Limbersky O, Folwaczny C 2004. Toll-like receptor (TLR) 2 and 4 mutations in peridontal disease. Clin Exp Immunol 135: 330-335.

Gauderman WJ, Morrison JM. QUANTO 1.1: A computer program for power and sample size calculations for genetic-epidemiology studies [monograph on the Internet]. 2006 [cited 2007 Nov 20]. Available from: http://hydra.usc.edu/gxe.

Gazzinelli RT, Ropert C, Campos MA 2004. Role of the Toll/interleukin-1 receptor signaling pathway in host resistance and pathogenesis during infection with protozoan parasites. Immunol Rev 201: 9-25.

Genc MR, Vardhana S, Delaney ML, Onderdonk A, Tuomala R, Norwitz E, Witkin SS 2004. Relationship between a Toll-like receptor-4 gene polymorphism, bacterial vaginosis-related flora and vaginal cytokine responses in pregnant women. Eur J Obstet Gynecol Reprod Biol 116: 152-156.

Guhl F 1999. Estado actual del control de la enfermedad de Chagas en Colombia. Medicina (B Aires) 59 (Supl. 2): 103-116.

Gutiérrez R, Angulo VM, Tarazona Z, Britto C, Fernandes O 2004. Comparison of four serological test for the diagnosis of Chagas Disease in a Colombian endemic area. Parasitol 129: 439-444.

Hartl DL, Clark AG 1989. Principles of population genetics, 2nd ed., Sinauer Associate, Sunderland, $681 \mathrm{pp}$.

Kang TJ, Chae GT 2001. Detection of Toll-like receptor 2 (TLR2) mutation in the lepromatous leprosy patients. FEMS Immunol Med Microbiol 31: 53-58.

Krishnegowda G, Hajjar AM, Zhu J, Douglass EJ, Uematsu S, Akira S, Woods AS, Gowda DC 2005. Induction of proinflammatory responses in macrophages by the glycosylphosphatidylinositols of Plasmodium falciparum: cell signaling receptors, glycosylphosphatidylinositol (GPI) structural requirement, and regulation of GPI activity. J Biol Chem 280: 8606-8616.

Lorenz E, Frees KL, Schwartz DA 2001. Determination of the TLR4 genotype using allele-specific PCR. Biotechniques 31: 22-24.

Lorenz E, Mira JP, Frees KL, Schwartz DA 2002. Relevance of mutations in the TLR4 receptor in patients with gram-negative septic shock. Arch Intern Med 162: 1028-1032.

Messias-Reason IJ, Urbanetz L, Pereira da Cunha C 2003. Complement $\mathrm{C} 3 \mathrm{~F}$ and BFS allotypes are risk factors for Chagas disease cardiomyopathy. Tissue Antigens 62: 308-312.

Miller SA, Dykes DD, Polesky HF 1988. A simple salting out procedure for extracting DNA from human nucleated cells. Nucleic Acids Res 16: 1215.

Mockenhaupt FP, Cramer JP, Hamann L, Stegemann MS, Eckert J,
Oh NR, Otchwemah RN, Diez E, Ehrhardt S, Schröder NWJ, Bienzle U, Schumann RR 2006. Toll-like receptor (TLR) polymorphisms in African children: Common TLR-4 variants predispose to severe malaria. Proc Natl Acad Sci USA 103: 177-182.

Nieto A, Beraun Y, Collado MD, Caballero A, Alonso A, Gonzalez A, Martin J 2000. HLA haplotypes are associated with differential susceptibility to Trypanosoma cruzi infection. Tissue Antigens 55: 195-198.

Ogus AC, Yoldas B, Ozdemir T, Uguz A, Olcen S, Keser I, Coskun M, Cilli A, Yegin O 2004. The Arg753GLn polymorphism of the human Toll-like receptor 2 gene in tuberculosis disease. Eur Respir J 23: 219-223.

Oliveira AC, Peixoto JR, Arruda LC, Campos MA, Gazzinelli RT, Golenbock DT, Akira S, Previato JO, Mendonca-Previato L, Nobrega A, Bellio M 2004. Expression of functional TLR4 confers proinflammatory responsiveness to Trypanosoma cruzi glycoinositolphospholipids and higher resistance to infection with T. cruzi. J Immunol 173: 5688-5696.

Ouassi A, Guilvard E, Delneste Y, Caron G, Magistrelli G, Herbault N, Tieblemont N, Jeannin P 2002. The Trypanosoma cruzi Tc52released protein induces human dendritic cell maturation signals via Toll-like receptor 2, and confers protection against lethal infection. J Immunol 168: 6366-6374.

Ramasawmy R, Cunha-Neto E, Faé KC, Muller NG, Cavalcanti VN, Drigo SA, Ianni B, Mady C, Kalil J, Goldenberg AC 2006. BAT1, a putative anti-inflammatory gene, is associated with chronic Chagas cardiomyopathy. J Infect Dis 193: 1394-1399.

Rocha MO 2003. Clinical management of chronic Chagas cardiomyopathy. Front Biosci 8: 44-54.

Sánchez E, Orozco G, López-Nevot MA, Jiménez-Alonso J, Martín J 2004. Polymorphisms of toll-like receptor 2 and 4 genes in rheumatoid arthritis and systemic lupus erythematosus. Tissue Antigens 63: 54-57.

Schneider S, Roessli D, Excoffier L 2000. Arlequin ver. 2000 : A software for population genetics data analysis, Genetics and Biometry Laboratory, University of Geneva, Switzerland.

Schroder NWJ, Hermann C, Hamann L, Gobel UB, HartungT, Schumann RR 2003. High frequency of polymorphism Arg753Gln of the Toll-like receptor- 2 gene detected by a novel allele-specific PCR. J Mol Med 81: 368-372.

Schroder NWJ, Meister D, Wolff V, Christan C, Kaner D, Haban V, Purucker P, Hermann C, Moter A, Gobel UB, Schumann RR 2005. Chronic periodontal disease is associated with single-nucleotide polymorphisms of the human TLR-4 gene. Genes Immun 6: 448-451

Shoda LK, Kegerreis KA, Suarez CE, Roditi I, Corral RS, Bertot GM, Norimine J, Brown WC 2001. DNA from protozoan parasites Babesia bovis, Trypanosoma cruzi, and T. brucei is mitogenic for B lymphocytes and stimulates macrophage expression of interleukin-12, tumor necrosis factor $\alpha$, and nitric oxide. Infect Immun 69: 2162-2171.

Takeda K, Akira S 2005. Toll-like receptors in innate immunity. Int Immunol 17: 1-14.

Takeda K, Kaisho T, Akira S 2003. Toll-like receptors. Annu Rev Immunol 21: 335-376.

WHO Expert Committee 2002. Control of Chagas Disease. World Health Organ Tech Rep Ser 905: 1-109.

Zafra G, Morillo C, Martin J, Gonzalez A, Gonzalez CI 2007. Polymorphism in the 3' UTR of the IL12B gene is associated with Chagas' disease cardiomyopathy. Microbes Infect 9: 1049-1052. 